\title{
Faculty led study abroad: Influences on student intercultural communication, interprofessional attitudes, and professional identity
}

\author{
Lynne Andonian * Ruth Rosenblum \\ College of Arts and Sciences, San Jose State University, San Jose, CA, United States
}

Received: May 8, 2017

DOI: $10.5430 /$ jnep.v7n11p1

\author{
Accepted: May 24, 2017 \\ Online Published: May 31, 2017 \\ URL: https://doi.org/10.5430/jnep.v7n11p1
}

\begin{abstract}
Interprofessional education is valued within healthcare professional programs as reflected in accreditation standards and program outcomes as well as college-wide initiatives. Little is known about the relationships between interprofessional attitudes among healthcare students (nursing, occupational therapy, social work), their degree of intercultural communication skills, and their professional identity. Thirty three students participating in interprofessional faculty-led study abroad completed pre- and postmeasures of the constructs under study: interprofessional attitudes, intercultural communication, and professional identity. Statistically significant positive relationships were found between interprofessional attitudes and intercultural communication skills which are discussed as well as implications for education and practice. This quantitative, descriptive study explored relationships between the variables which included cultural communication, interprofessional attitudes, and professional identity. This study supports the need for interprofessional exposure and experience for healthcare students. Educational pedagogy and practices will need to be adjusted to allow for increased emphasis on these variables, specifically for students in service-oriented health related fields.
\end{abstract}

Key Words: Interprofessional, Culture, Education, Study abroad, International

\section{INTRODUCTION}

The need for international and interprofessional learning opportunities within healthcare education has been identified by the World Health Organization ${ }^{[1]}$ and are supported by national professional standards of accreditation. ${ }^{[1,2]}$ Interprofessional learning opportunities support students' preparation to work within healthcare disciplines such as nursing, social work, and occupational therapy. At one public university, the college focused on health professions, programming has been initiated to foster and encourage international experiences for all students within the college. This college has strongly supported interprofessional international experiences for its graduates because it is believed that health providers and others working in people-oriented professions are better equipped to work with diverse populations having had international experiences which broaden one's world view. The study goals include learning more about how international experiences in higher education may affect students' intercultural communication, interprofessional attitudes, and professional identity. At present, no studies exist in the published literature regarding the effect of these three elements.

*Correspondence: Lynne Andonian; Email: lynne.andonian@sjsu.edu; Address: Department of Occupational Therapy, San Jose State University, San Jose, CA, United States. 


\subsection{Research purpose and importance}

Limited research in the literature explores the concept of professional identity coupled with international experiences. The purpose of this study is to measure how such experiences may influence three critical skills related to students' capacity to work in diverse settings: 1) learning intercultural communication, 2) developing attitudes that enable interprofessional collaboration, and 3) developing a sense of professional identity.

The study investigated the following hypotheses: 1) An international educational experience will significantly affect students' self-report of intercultural communication; 2) An international educational experience will significantly affect students' reported development of attitudes which support interprofessional collaboration; 3) An international educational experience will significantly affect students' reported development of professional identity; 4) Students' degree of intercultural communication, interprofessional attitudes, and development of professional identity will be significantly and positively correlated.

\subsection{Background/review of literature}

There are many models offered in the literature for global health competencies, competency-based global health education, and interprofessional competencies for global health education. ${ }^{[3-6]}$ Most of these competencies use service learning as the basis for the framework, with students participating in experiential education to maximize student development while addressing community needs and priorities. While it is challenging to extricate the student experience from community needs, for this article we will be concentrating solely on elements related to intercultural communication, professional identity, and interprofessional attitudes. Arthur, Battat, and Brewer ${ }^{[7]}$ describe global health competencies for medicine and nursing. Ablah et al. ${ }^{[3]}$ in conjunction with the Association of Schools of Public Health, offers competencies including knowledge, skills and attitudes needed for performance in the current global health workforce for master-level students in a health field. Their Global Health Competency Model 1.1 proposes specific skills applicable to global health practice "regardless of the context, location, or scale of the work." It emphasizes that practitioners be able to synthesize the competencies, globally or locally, inside and outside the borders of one's home or host country. Their model promotes global health and well-being by enhancing students' health competence. Again, this model does not directly address our study purpose. However, in the 7 domains offered, several of them directly 'connect the dots' to our purpose of examining critical skills related to intercultural communication, professional identity, and interprofessional attitudes.
The 7 domains offered include the following: 1) Capacity Strengthening, 2) Collaborating and Partnering, 3) Ethical Reasoning and Professional Practice, 4) Health Equity and Social Justice, 5) Program Management, 6) Socio-cultural and Political Awareness, and 7) Strategic Analysis. Capacity Strengthening and Collaborating and Partnering are most applicable to the data offered from our research.

Jogerst and Callender et al. ${ }^{[8]}$ describe a global health competency framework for 21 st century health professionals as part of their work with the Consortium of Universities for Global Health. These competencies are similar to those described above but include additional domains of the globalization of health and health care and discussing the global burden of disease. They offer advice to institutions developing global health curricula to specifically focus on interprofessional collaboration as a key to address current and potential health challenges. An interesting perspective offered is that these competencies have a bias towards North American students and were developed by universities in North America. It is imperative that we discuss competencies, and intercultural communication, professional identity, and interprofessional attitudes from the North American and host country perspectives. To this end, Kulbok and Mitchell et al. ${ }^{[9]}$ recommend that students and faculty work collaboratively and participate in two-way exchanges to build capacity at both institutions. Additionally, strengthening intercultural communication and examining interprofessional attitudes and professional identity in various fields, is explored as it relates to countries with vastly different education and health care systems. Intercultural communication can be strengthened by mutual goals and activities, both academic and social. These are key aspects of the Faculty Led Program (FLP) experience which serves to develop attitudes that enable interprofessional collaboration and a sense of professional identity for students' emerging professional role.

International and interprofessional learning opportunities in healthcare can contribute to cultural competence and humility while enhancing a student's ability to promote optimal outcomes. This occurs by student synthesis of their role identity as a provider of health care in a setting which may or may not be familiar, and with clients and coworkers who possess different cultural heritages and beliefs. Smith-Miller, Leak et al. ${ }^{[10]}$ described student reflection papers from a short-term international experience and how critical examination of the experience may translate to the workplace. In their article, and in our experience, students self-select for FLP participation, which may bias data and results to those already willing to leave their 'comfort zone'. They identify that personal growth and professional competence from these experiences are profound and may have immediate application in the 
clinical setting for participants.

As previously stated, exploration of professional identity was a purpose of this study. Hao et al. ${ }^{[11]}$ developed a tool, the Professional Identity Scale for Nursing Students (PISNS), and tested it for reliability and validity. This tool was developed to measure professional identity in Chinese nursing students, who display low professional identity. This tool and the manuscript describing it is not related to intercultural communication or interprofessional attitudes, but it does offer a new instrument for measuring the professional identity of nursing students. It has a bias towards Chinese nursing students with a Chinese cultural background. Their article and concept illustrates the need for similar tools to be used in the global health education arena.

Finally, Liu, Zhang et al. ${ }^{[12]}$ identify gaps in global health education via an empirical literature review. They found four gaps after examining 238 articles. The gaps included: Trending of studies on global health education increasing over the past 10 years, a gap in study quantity and quality in global health education, a gap in education approaches to global health education, and a gap in standardization of global health education. Global health education and global service learning are often used synonymously. One needs to define who is the recipient of the education - the health care providers or care recipients, and if traditional education is the goal or if education via service learning is the emphasis. One center defines global health work as 'work that addresses the global root causes and global impacts of health challenges and disparities, wherever they occur'. [6] This is the definition that best fits the study discussed here, which is focused upon the education of healthcare providers. They identify a lack of consensus on contents and approaches and further offer that global health education could be a potent tool for ultimately improving health equity and reducing disparities. Recommendations include integrating 'global education' into medical and other undergraduate and graduate education. They conclude that interdisciplinary approaches and interprofessional care are encouraged but do not directly address professional identity or how to operationalize these recommendations.

\section{Methods}

\subsection{Recruitment}

The subject population included all genders, age 18+, of any race or ethnicity who participated in a FLP course in summer 2016 within the college of a public urban university. The recruitment email was sent to all 162 students in the college who were registered for FLP and included the following student majors: nursing, occupational therapy, social work, kinesiology, communications, journalism, and nutri- tion. Nearly all participants who registered for FLP courses were students, yet community members such as practicing clinicians, alumni, or students from other universities were eligible to participate in these courses, too. The FLP courses in the college included varied topics in locations such as Finland, Malta, Taiwan, Grenada, and Ireland. Some programs were cultural exchanges, while others had a service-learning emphasis. This meant that some students experienced locations with languages different from their own. This cohort complements the study goals of examining the effect of international educational experiences on students' cultural communication, interprofessional attitudes, and professional identity.

\subsection{Study design}

This quantitative study used correlation to explore relationships between the variables in the study: 1) cultural communication, 2) interprofessional attitudes, and 3) professional identity.

\subsection{Procedures}

Institutional Review Board approval was secured by the researcher. The researcher sent an email to the 162 students enrolled in the college's summer FLP courses inviting them to participate in a research study investigating intercultural communication, interprofessional attitudes, and professional identity. Students were alerted that the decision to participate, or not, was voluntary and confidential. Students were instructed to click on a link within the email to access the Qualtrics survey, then clicked on a link that indicated they gave their consent to participate in the study. Students were identified with the data via an assigned number that enabled the pre-FLP survey and post-FLP survey data to be linked with the subject. The pre-survey occurred prior to participation in the FLP and the post-survey occurred after the completion of the FLP. All FLP's in this college incorporated academic and social elements, although each FLP had different curricula. All FLPs offered were consistent with best practices related to pre-departure activities, on-site seminars, and post-experience reflections to guide students in processing their experiences. Students were asked to complete 3 measures on the survey: 1) the Intercultural Communication Competence Scale, ${ }^{[13]}$ 2) the Interprofessional Attitudes Scale, ${ }^{[14]}$ and 3) the Macleod Clark Professional Identity Scale. ${ }^{[15]}$ After they completed the survey, students were informed they would be contacted via email after the FLP course to take the post-test.

\subsection{Measures}

The study used three measures. The Intercultural Communication Competence Scale questionnaire is composed of 
21 items, where participants respond on a 5-point Likert scale: $1=$ strongly disagree, and $5=$ strongly agree. A total score is determined and four subscales are identified: 1) Attitude towards other cultures, 2) Ethnocentrism, 3) Motivation and 4) Interaction involvement. ${ }^{[13]}$ The Interprofessional Attitudes Scale (IPAS) consists of a 27 -items questionnaire that uses a five-point Likert-type scale to measure attitudes toward interprofessional cooperation on five subscales: 1) Teamwork, roles, and responsibilities, 2) Patientcenteredness, 3) Interprofessional biases, 4) Diversity and ethics, and 5) Community centeredness. ${ }^{[14]}$ The Macleod Clark Professional Identity Scale is composed of nine items on a six-point Likert scale: $1=$ strongly disagree and $6=$ strongly agree. ${ }^{[15]}$ Data were collected, stored, and analyzed via Qualtrics which is accessible by secure login only by the researcher or research assistants.

\section{Results}

Thirty-three participants completed both the pre and posttests of all three measures used in the study: the Intercultural Communication Competence Scale, the Interprofessional Attitudes Scale, and the Macleod Clark Professional Identity Scale. Here are the study results for each hypothesis:

Hypothesis 1) An international educational experience will significantly affect students' self-report of intercultural communication. There were no significant changes in pre-test and post-test scores in Intercultural Communication Competence Scale scores.

Hypothesis 2) An international educational experience will significantly affect students' reported development of attitudes which support interprofessional collaboration. For the overall group of 33 students, no significant changes in pre-test and post-test interprofessional attitudes scores were indicated. However for the 22 respondents (out of the 33 total) who indicated that they had no prior interprofessional experiences/training prior to joining the FLP course, the data indicate a significant and positive change in the IPAS subscore of Teamwork from the pre-test score in comparison to the post-test score $(p=.045)$. Thus, after the faculty led study abroad course, students without prior interprofessional experiences may have felt better prepared to engage in interprofessional teamwork activities.

Hypothesis 3) An international educational experience will significantly affect students' reported development of professional identity. There were no significant changes in professional identity scores from the pre-test to the post-test.

Hypothesis 4) Students' degree of cultural communication, interprofessional attitudes, and development of professional identity will be significantly and positively correlated. There were no significant correlations between professional identity and intercultural communication or interprofessional attitudes. Both the pre-test and post-test total scores of the IPAS were positively correlated with the overall score of the Intercultural Communication Competence Scale $(p<.001)$. The pre-test score of the IPAS focused on teamwork was positively and significantly correlated with the total Intercultural Communication Competence score $p=.004$. The ability to perform well in an interprofessional group may be related to good communication skills that take differences into account as measured by the Intercultural Communication Competence. This may indicate that students choosing to participate in faculty led study abroad may have developed skills in or interest in intercultural communication.

The results provide descriptive statistics about the study subjects who had limited changes in their pre and post faculty led study abroad skills as measured in professional identity, interprofessional attitudes, and intercultural communication.

\section{Discussion}

The study results illuminate that students who participate in faculty led study abroad courses may be those who already have a particular interest in interprofessional issues and some awareness of cultural differences and intercultural communication skills. It's interesting to note that the college is in the process of requiring an international experience for all students, which may mediate the self-selection argument. All students will be expected to have an international experience prior to graduation and many students in the study are within departments that already require an international experience.

The importance of interprofessional attitudes and its positive and significant relationship to intercultural communication skills, has implications for collegial relationships, work environment, and service delivery. A cohesive and communicative healthcare team delivers better care with improved patient outcomes. ${ }^{[16]}$ Self-reflection is linked with both interprofessional practice and professional identity. Interprofessional FLP experiences that include teaching self-reflective strategies, in which students learn about their own thinking, worldview, and assumptions explicitly, may help students to develop their own professional identity, awareness of interprofessional roles, and skills in providing care as part of a healthcare team.

The change in interprofessional teamwork scores was significant and improved for those students without any prior interprofessional experience. This may support the need for interprofessional exposure and experience during academic preparation for healthcare students. Development of these skills is needed - at home or abroad - to promote interpro- 
fessional teamwork best practices. This may have repercussions for student selection criteria for interprofessional FLP courses. It may behoove students without interprofessional exposure to select FLP courses that have an interprofessional component to best prepare for interprofessional teamwork within their future practice settings. Further, the literature describes difficulty in measuring growth or change in interprofessional attitudes, ${ }^{[17]}$ many measures have been criticized as not being sensitive to change and this concern may put this inquiry's results into perspective-perhaps there were greater changes that simply were not captured by the available measures. Defining global health work as 'work that addresses the global root causes and global impacts of health challenges and disparities, wherever they occur ${ }^{\text {'[6] encom- }}$ passes the concept of interprofessional teamwork. Students and professionals in healthcare related fields never work alone, it is via teamwork and interprofessional, international understanding that populations receive the care they need.

\section{Limitations \& recommendations for future research}

The limitations of the study are the small sample size ( $\mathrm{n}=$ 33) and the focus upon just one college within a public urban university. Directions for future research include incorporat- ing more sensitive measures of change in perspectives such as the Global Perspectives Inventory and including other disciplines within the college such as kinesiology and nutrition. Future research may also include more colleges on the campus that also address service professions such as education and teacher programs and speech pathology, which are housed in different colleges than included in this inquiry.

\section{Conclusions}

This quantitative, descriptive study explored relationships between the variables which included intercultural communication, interprofessional attitudes, and professional identity. While few of the findings were statistically significant, this study supports the need for interprofessional exposure and experience for healthcare students on ours and other campuses. Educational pedagogy and practices will need to be adjusted to allow for increased emphasis on these variables, specifically for students in service-oriented health related fields.

\section{Conflicts of InTEREST Disclosure}

The authors declare that there is no conflict of interest.

\section{REFERENCES}

[1] Baker PG. Framework for action on interprofessional education and collaborative practice. 2010. Avaiable from: http://www . who. in t/hrh/nursing_midwifery/en/

[2] 2011 Accreditation Council for Occupational Therapy Education (ACOTE®) Standards. Am J Occup Ther. 2012; 66(6 Supplement): S6-S74. https://doi.org/10.5014/ajot.2012.66S6

[3] Ablah E, Biberman DA, Weist EM, et al. Improving global health education: development of a global health competency model. The American Journal of Tropical Medicine and Hygiene. 2014 Mar 5; 90(3): 560-5. https : //doi .org/10.4269/ajtmh.13-0537

[4] McKinnon T, Smedley CT, Evert J. Service Learning as a Framework for Competency-Based Local/Global Health Education. Annals of Global Health. 2016 Nov 1; 82(6): 1034-42. PMid:28314490 https://doi.org/10.1016/j.aogh.2016.11.004

[5] McKinnon TH, Fealy G. CORE PRINCIPLES for Developing Global Service-Learning Programs in Nursing. Nursing Education Perspectives. 2011 Mar 1; 32(2): 95-101. PMid:21667790 https: //doi.org/10.5480/1536-5026-32.2.95

[6] Brown LD. Towards defining interprofessional competencies for Global Health Education: drawing on educational frameworks and the experience of the UW-Madison Global Health Institute. The Journal of Law, Medicine \& Ethics. 2014 Dec; 42(2suppl): 32-7. https://doi.org/10.1111/jlme.12185

[7] Arthur MA, Battat R, Brewer TF. Teaching the basics: core competencies in global health. Infectious disease clinics of North America. 2011 Jun 30; 25(2): 347-58. https ://doi .org/10.1016/j.idc. 2011.02 .013

Published by Sciedu Press
[8] Jogerst K, Callender B, Adams V, et al. Identifying interprofessional global health competencies for 21 st-century health professionals. Annals of Global Health. 2015 Apr 30; 81(2): 239-47. https ://doi.org/10.1016/j.aogh.2015.03.006

[9] Kulbok PA, Mitchell EM, Glick DF, et al. International experiences in nursing education: A review of the literature. International Journal of Nursing Education Scholarship. 2012 Jan; 9(1): 1-21. https://doi.org/10.1515/1548-923X. 2365

[10] Smith-Miller CA, Leak A, Harlan CA, et al. "Leaving the Comfort of the Familiar": Fostering Workplace Cultural Awareness Through Short-Term Global Experiences. In Nursing Forum. 2010; 45(1): 1828. https://doi.org/10.1111/j.1744-6198.2009.00163.x

[11] Hao YF, Niu HJ, Li LP, et al. Measurement of professional identity in Chinese nursing students. International Journal of Nursing Sciences. 2014 Jun 30; 1(2): 137-44.

[12] Liu Y, Zhang Y, Liu Z, et al. Gaps in studies of global health education: an empirical literature review. Global health action. $2015 \mathrm{Apr}$ 21; 8. https://doi.org/10.3402/gha.v8.25709

[13] Arasaratnam LA. The development of a new instrument of intercultural communication competence. Journal of Intercultural Communication. 2009 May; 5(20). https ://doi.org/10.1016/j.ijintr el.2015.03.001

[14] Norris J, Carpenter MJ, Eaton MJ, et al. Development and construct validation of the interprofessional attitudes scale. Academic medicine: journal of the Association of American Medical Colleges. 2015 Oct; 90(10): 1394. https://doi.org/10.1097/ACM.000000000000 0764

[15] Adams K, Hean S, Sturgis P, et al. Investigating the factors influencing professional identity of first-year health and social care stu- 
dents. Learning in Health and Social Care. 2006 Jun 1; 5(2): 55-68. https://doi.org/10.1097/ACM. 0000000000000764

[16] Strasser DC, Falconer JA, Herrin JS, et al. Team functioning and patient outcomes in stroke rehabilitation. Archives of Physical Medicine Rehabilitation. 2005 March; 86: 403-409. https://doi.org/10
$.1016 / j$.apmr. 2004.04.046

[17] Thannhauser J, Russell-Mayhew S, Scott C. Measures of interprofessional education and collaboration. Journal of Interprofessional Care. 2010 Jul 1; 24(4): 336-49. https://doi .org/10.3109/135618 20903442903 